\title{
Proteína $C$ reactiva, síndrome metabólico y riesgo cardiovascular en la población costarricense nacida entre 1945 y 1955
}

\author{
Eduardo Aguilar Fernández ${ }^{1}$ (D) \& Ana Maricela Carballo Alfaro²
}

1. Universidad Nacional, Facultad de Ciencias Exactas y Naturales, Escuela de Matemática, Heredia, Costa Rica; eduardo.aguilar.fernandez@una.cr

2. Hospital Nacional de Geriatría y Gerontología, Departamento de Farmacia, San José, Costa Rica; anamaricelac@hotmail.com

Recibido 24-X-2019 • Corregido 17-II-2020 • Aceptado 28-II-2020

DOI: https://doi.org/10.22458/ urj.v12i1.2662

\begin{abstract}
C$ reactive protein, metabolic syndrome and cardiovascular risk in the Costa Rican population born between 1945 and 1955". Introduction: Several studies have mentioned that there is a relationship between $C$ reactive protein (CRP) and the metabolic syndrome (MS) and that this protein is a risk factor of cardiovascular disease. Objective: We studied the relationship of CRP with MS in the Costa Rican population. Methods: People born in Costa Rica between 1945 and 1955 and participants in CRELES-RC project were included in the study ( $n=2$ 273). MS was adapted according to the American Heart Association and National Heart, Lung and Blood Institute definition. Results: The prevalence of MS increased with elevated CRP levels $(p<0,001)$ and was higher in women $(p<0,001)$. CRP was independently and positively associated to waist circumference and negatively associated to HDL-cholesterol. The strongest CRP determinant was waist circumference (PSup $=67,8$ ). After adjustment for age, sex, residence area, smoking and alcohol, in the highest quartile of CRP levels (CRP> 4 $\mathrm{mg} / \mathrm{L}$ ), the risk for MS was higher compared with that in the lowest quartile of CRP levels. Cardiovascular risk was higher in people with high levels of CRP. Conclusions: CRP levels is associated with the MS among Costa Ricans born between 1945 and 1955.
\end{abstract}

Keywords: Risk factors, central obesity, high blood pressure, dyslipidemia, hyperglycemia, Costa Rica.
RESUMEN. Introducción: Varios estudios han mencionado que existe relación entre la proteína $C$ reactiva (PCR) y el síndrome metabólico (SM) y que esta proteína es un factor de riesgo de enfermedad cardiovascular. Objetivo: Se estudió la relación entre la PCR y el SM en la población costarricense. Métodos: Se consideraron 2273 personas nacidas en Costa Rica entre 1945 y 1955 participantes en el proyecto CRELES-RC. La definición del SM fue una adaptación de los criterios establecidos por la American Heart Association and National Heart, Lung and Blood Institute. Resultados: La prevalencia del SM aumenta conforme incrementan los niveles de PCR $(p<0,001)$ y esta prevalencia fue mayor en las mujeres $(p<0,001)$. La PCR se asoció en forma independiente y positiva con la circunferencia de la cintura y negativa con el colesterol HDL (C-HDL). La asociación más fuerte fue con la circunferencia de la cintura (probabilidad de superioridad (PSup) de 67,8). Después de ajustar por edad, sexo, zona de residencia, tabaquismo y consumo de bebidas alcohólicas, las personas con niveles de PCR ubicados en el cuarto cuartil tienen mayor riesgo de presentar SM en comparación con las que muestran niveles de PCR ubicados en el primer cuartil. Por otro lado, el riesgo cardiovascular fue más alto en personas con altos niveles de PCR. Conclusiones: La PCR está asociada con el SM en las personas costarricenses nacidas entre 1945 y 1955.

Palaras clave: Factor de riesgo, obesidad central, presión sanguínea elevada, dislipidemia, hiperglucemia, Costa Rica. 
El síndrome metabólico (SM) está caracterizado por la presencia en la persona de una serie de factores de riesgo que incluye la obesidad abdominal, presión sanguínea elevada, dislipidemia e hiperglucemia (Ye et al., 2007). Se ha considerado que las personas con SM tienen mayor riesgo de padecer enfermedad cardiovascular (Sattar et al., 2003).

La proteína $C$ reactiva (PCR) es un marcador típico de inflamación que ha sido asociado con enfermedades cardiovasculares (Koenig et al., 1999; Ridker, Buring, Cook, \& Rifai, 2003; Danesh et al., 2004). Se ha determinado que las mediciones de PCR aumentan las estimaciones de puntuación del riesgo cardiovascular de Framingham, así como la capacidad predictiva de los factores de riesgo cardiovascular tradicionales (Ridker, Rifai, Rose, Buring, \& Cook, 2002; Albert, Glynn, \& Ridker, 2003). Las relaciones encontradas entre PCR y enfermedad cardiovascular han permitido establecer un consenso por parte de la American Heart Association (AHA) y los Centers for Disease Control (CDC) para que se realicen pruebas de PCR de alta sensibilidad para evaluar el riesgo cardiovascular, estableciéndose que los niveles de concentración $<1 \mathrm{mg} / \mathrm{L}$ indican bajo riesgo, de 1 a 3mg/L señalan riesgo medio y superiores de $3 \mathrm{mg} / \mathrm{L}$ son indicadores de un riesgo elevado (Ridker, 2003).

Además, se ha mencionado que existe relación entre PCR y componentes individuales del SM (Mendall, Patel, Ballam, Strachan, \& Northfield, 1996; Yudkin, Stehouwer, Emeis, \& Coppack, 1999). Por otra parte, la presencia de SM está asociada con altos niveles de PCR (Fröhlich et al., 2000; Rutter, Meigs, Sullivan, D’Agostino, \& Wilson, 2004; Arcari et al., 2008). También se ha observado que las concentraciones de PCR son más elevadas conforme aumenta la cantidad de componentes del síndrome metabólico (Fröhlich et al., 2000, Ye et al., 2007, Yang et al., 2013).

El propósito de la investigación consistió en estudiar la PCR y su asociación con el síndrome metabólico y sus componentes en la población costarricense nacida entre 1945 y 1955 . Además, se estimó el riesgo cardiovascular y se comparó para los distintos niveles de PCR.

\section{MATERIALES Y MÉTODOS}

Datos: CRELES-RC, Costa Rica: Estudio de Longevidad y Envejecimiento Saludable, el cual es un proyecto que involucra una nueva cohorte de jubilación nacida entre 1945 y 1955 y está compuesto por 2798 entrevistas realizadas entre enero de 2010 y diciembre de 2011. Este proyecto empleó un diseño de muestreo probabilístico con cuatro etapas. Fue desarrollado por la Universidad de California en Berkeley y el Centro Centroamericano de Población (CCP) de la Universidad de Costa Rica con fondos del Instituto Nacional sobre el Envejecimiento de los Estados Unidos (subvención NIH R01 AG031716). CRELES-RC fue aprobado en abril de 2009 por el Comité para la Protección de Sujetos Humanos (CPHS II) de la Universidad de California en Berkeley. El estudio y los procedimientos para el trabajo de campo y el consentimiento informado también fueron aprobados por el Comité de Ciencia Ética de la Universidad de Costa Rica en las sesiones celebradas el 24 de abril de 2009, el 10 de agosto de 2009 y el 23 de febrero de 2011 (referencias: VI-2878- 2009, VI5308-2009 y VI-1313-2012), como parte del proyecto de investigación número 828-A2 -825. Todas las bases de datos del proyecto están disponibles para el público en la dirección electrónica http://www.creles.berkeley.edu:1313/CRdata.pl y se han hecho anónimas (se eliminaron el nombre y otros identificadores) para evitar riesgos para la privacidad de las personas participantes. El consentimiento informado por escrito se firmó durante la primera ola de entrevistas, en la que se explicó la ocurrencia de visitas de seguimiento después de dos años (Dow, Brenes, \& Rosero, 2013).

En esta investigación se consideró una muestra de 273 personas participantes en CRELES$\mathrm{RC}$ para las cuales, las mediciones en las variables consideradas en este estudio estaban disponibles.

Variables sociodemográficas: Para la investigación se consideró la edad, la zona de residencia en dos categorías (urbana o rural), el área de residencia (gran área metropolitana u otra), la condición de persona fumadora (tabaquismo) en dos categorías (sí o no) y consumo de bebidas 
alcohólicas (alcohol) en dos categorías (sí o no). El nivel de escolaridad se definió a partir de los años de educación considerando dos categorías: 6 años o menos y más de 6 años de educación recibida.

Medidas antropométricas y biomarcadores: En la ejecución de CRELES-RC se realizaron dos mediciones para la presión arterial durante la entrevista principal, con un intervalo de tiempo promedio de 20 minutos entre cada una. La medición se realizó utilizando monitores digitales de marca OMRON con inflado automático, modelo HEM-711 (precisión: $\pm 3 \mathrm{mmHg}$ ) que se calibraron periódicamente. La circunferencia de la cintura fue medida con la persona de pie, en una posición semianatómica (con los pies separados y la palma de las manos apoyadas en el muslo lateral). En esta medición se utilizaron cintas métricas de la marca Quick Medical. Las muestras de sangre fueron obtenidas por venopunción sin considerar ayuno y la mayoría poco después de la entrevista. Se tomaron dos tubos de muestras de sangre: uno con anticoagulante (VACUTAINER / EDTA) de 3$4 \mathrm{~mL}$ que se centrifugó más tarde para separar el plasma de las células y otro tubo sin anticoagulante con activador del coagulo (VACUTAINER SST, $5 \mathrm{~mL}$ ) para obtener suero. Para pruebas de colesterol total (CT), colesterol HDL (C-HDL) y PCR se separó en el laboratorio una fracción de suero en un tubo cónico tipo Eppendorf y para el análisis de la hemoglobina glicosilada (HbA1c) se consideró $1 \mathrm{~mL}$ de sangre completa en el tubo EDTA. Estas mediciones de los biomarcadores fueron analizados en el laboratorio clínico de la Oficina de Salud y Bienestar Estudiantil de la Universidad de Costa Rica (UCR) (Dow et al., 2013).

En la presente investigación se consideró las mediciones aportadas en la base de datos de CRELES-RC para los biomarcadores y la circunferencia de la cintura. Para la presión arterial se utilizó como valor final la media aritmética de las dos mediciones que se realizaron en CRELES-RC.

Definición del síndrome metabólico y riesgo cardiovascular: Para definir el síndrome metabólico se consideraron los criterios establecidos por la American Heart Association (AHA) y el National Heart, Lung and Blood Institute (NHLBI) (Grundy et al., 2005), los cuales indican que la presencia de tres o más de los siguientes factores de riesgo son indicadores para el diagnostico del SM: obesidad abdominal con circunferencia de la cintura $\geq 102 \mathrm{~cm}$ en hombres $y \geq 88 \mathrm{~cm}$ en mujeres, triglicéridos $\geq 150 \mathrm{mg} / \mathrm{dL}$, colesterol transportado por lipoproteína de alta densidad (C-HDL) $\leq 40$ $\mathrm{mg} / \mathrm{dL}$ en hombres y $\leq 50 \mathrm{mg} / \mathrm{dL}$ en mujeres, presión arterial (PA) $\geq 130 / 85 \mathrm{mmHg}$ o tratamiento farmacológico para la hipertensión, glucosa en ayunas $\geq 100 \mathrm{mg} / \mathrm{dL}$. En la presente investigación se realizó una adaptación de la definición anterior incluyendo el nivel de CT $\geq 200 \mathrm{mg} / \mathrm{dL}$ en lugar de los triglicéridos y la hemoglobina glicosilada $\geq 6,5 \%$ en vez de la glucosa en ayunas.

El riesgo de sufrir evento cardiovascular en 10 años se estimó por medio de las tablas de riesgo de Framingham-Wilson, las cuales involucran variables como la edad, el sexo, el hábito de fumar, la presencia de diabetes, la presión arterial sistólica, el CT y el C-HDL (Wilson, D’Agostino, Levy, Belanger, \& Silbershatz, 1998).

Análisis estadístico: Para el análisis de los datos se utilizó el ANOVA para comparar los niveles medios de los distintos componentes del SM y el riesgo de sufrir evento cardiovascular por cuartil de PCR. La prevalencia del SM se calculó después de la estratificación por sexo, zona, área, educación, tabaquismo, alcohol y para cada uno de los factores de riesgo del SM respectivamente y se utilizó la prueba chi-cuadrado para evaluar la tendencia dentro de cada estrato.

Se calculó el coeficiente de correlación de Spearman para evaluar la relación entre la PCR y los componentes del SM y PCR con riesgo cardiovascular, se utilizó la probabilidad de superioridad con el fin de evaluar el tamaño del efecto de los distintos factores. Se empleó la prueba de suma de rangos de Wilcoxon para comparar los niveles de la mediana de la PCR en personas con y sin SM. Se utilizó la prueba de Kruskal-Wallis para evaluar la asociación de los niveles de la mediana de PCR y el número de componentes del síndrome metabólico.

Se utilizaron modelos de regresión logística multivariada para estimar los odds ratios (OR) para el SM y sus componentes. Las variables consideradas en los modelos fueron la edad (continua), 
el sexo, la zona de residencia, el tabaquismo, el consumo de alcohol, el nivel de escolaridad y cada uno de los componentes del síndrome metabólico.

En los análisis estadísticos se utilizó el programa STATA versión 13.1 (stat Corp. USA). Los valores $p<0,05$ fueron considerados significativos y se utilizó la probabilidad de superioridad (PSup) con el fin de evaluar el tamaño del efecto de los distintos factores.

Las personas que presentaron mediciones de PCR superiores a $10 \mathrm{mg} / \mathrm{L}(n=239)$ fueron excluidos de los análisis, ya que la consideración de estos valores puede introducir factores de confusión por la presencia de enfermedad inflamatoria aguda o crónica (Ridker, 2003).

Ética, conflicto de intereses y declaración de financiamiento: Las personas autoras declaran haber cumplido con todos los requisitos éticos y legales pertinentes, tanto durante el estudio como en el manuscrito; que no hay conflictos de interés de ningún tipo, y que todas las fuentes financieras se detallan plena y claramente en la sección de agradecimientos. Asimismo, están de acuerdo con la versión editada final del documento. El respectivo documento legal firmado se encuentra en los archivos de la revista.

\section{RESULTADOS}

La mediana de la PCR en la población de estudio resultó en $2 \mathrm{mg} / \mathrm{L}$ y los niveles de los factores del SM, excepto C-HDL, crecen conforme incrementa el nivel PCR (Cuadro 1).

La prevalencia del síndrome metabólico en la población de estudio es del 53,6\%. Por otro lado, la prevalencia es mayor en las mujeres, en residentes de zona urbana y del gran área metropolitana. No se observan diferencias importantes según el nivel de escolaridad. Además, el porcentaje de personas con síndrome metabólico incrementa progresivamente de $27 \%$ a $67 \%$ según aumenta el nivel de PCR. La tendencia se comporta similar en cada uno de los subgrupos analizados (sexo, zona, área y escolaridad), así como en los componentes del SM (Cuadro 2).

Si bien todos los componentes del SM mostraron una correlación significativa con la PCR, fue la circunferencia de la cintura la que presentó mayor fuerza en la asociación con un efecto de cierta relevancia con una probabilidad de superioridad de $67,5 \%$, lo que indica la presencia de un efecto moderado. En relación con los componentes del síndrome metabólico, la PCR mostró asociación importante con la circunferencia de la cintura, mientras que con los otros componentes la correlación es ligeramente pequeña (Cuadro 3).

Se determinó que el nivel de PCR es mayor en las personas con presencia de síndrome metabólico (Fig. 1), la diferencia resultó significativa $(p<0,001)$. Además, la probabilidad de que el nivel de PCR en una persona con síndrome metabólico sea mayor a una que no lo posee es de $61,6 \%$, la cual se aproxima a la presencia de un efecto moderado.

Se da un incremento significativo $(p<0,001)$ en el nivel de PCR con el aumento del número de componentes del SM (Fig. 2).

EI OR de presentar PCR> 3mg/L en personas con síndrome metabólico es de 1,95 (IC95\%: $1,59-2,38)$, luego de ajustar por edad, sexo, zona de residencia, escolaridad, tabaquismo y consumo de alcohol $(p<0,001)$. Además, los odds ratios para el síndrome metabólico y para algunos de sus componentes presentaron un incremento por cuartil de PCR. Al comparar las personas ubicadas en el cuartil más alto con las del cuartil más bajo, se presentaron odds ratios de 4,26 para el síndrome metabólico, 7,70 para la CC, 1,78 para elevada PS, 1,86 para CT elevado, 3,18 para bajo C-HDL y 1,68 para hiperglicemia, respectivamente después de ajustar por edad, sexo, zona, tabaquismo, consumo de alcohol y escolaridad (Cuadro 4). 


\section{CUADRO 1}

Características generales de la población nacida entre 1945 y 1955 por cuartil de PCR, Costa Rica

\begin{tabular}{|c|c|c|c|c|c|c|}
\hline \multirow[b]{2}{*}{ Variable } & \multicolumn{6}{|c|}{ Cuartil de PCR } \\
\hline & $\begin{array}{c}\text { Total } \\
\text { (n=2 273) }\end{array}$ & $\begin{array}{c}1 \\
<1,00 \\
(n=95)\end{array}$ & $\begin{array}{c}2 \\
1,00-2,99 \\
(n=654)\end{array}$ & $\begin{array}{c}3 \\
3,00-3,99 \\
(n=844)\end{array}$ & $\begin{array}{c}4 \\
\geq 4,00 \\
(n=680)\end{array}$ & $\begin{array}{c}\text { p para la } \\
\text { diferencia }\end{array}$ \\
\hline Edad (DE) & $59,7(3,2)$ & 59,9 & 59,8 & 59,7 & 59,5 & 0,389 \\
\hline$C C(D E)$ & $96,0(12,1)$ & 88,2 & 91,8 & 96,5 & 100,6 & $<0,001$ \\
\hline CT (DE) & $206,4(41,8)$ & 195,0 & 204,6 & 205,9 & 201,3 & 0,002 \\
\hline C-HDL (DE) & $41,9(12,3)$ & 44,5 & 42,9 & 41,8 & 40,8 & 0,002 \\
\hline P Sistólica (DE) & $139,7(20,5)$ & 136,8 & 137,7 & 140,4 & 141,6 & $<0,001$ \\
\hline P Diastólica (DE) & $81,2(11,1)$ & 79,1 & 80,0 & 81,2 & 82,6 & $<0,001$ \\
\hline HbA1c (DE) & $6,2(1,0)$ & 5,9 & 6,0 & 6,2 & 6,4 & $<0,001$ \\
\hline Sexo (\%) & & & & & & $<0,001$ \\
\hline Hombre & 40,5 & 6,7 & 37,3 & 35,5 & 28,1 & \\
\hline Mujer & 59,5 & 2,4 & 22,9 & 38,2 & 31,3 & \\
\hline Zona (\%) & & & & & & 0,286 \\
\hline Rural & 43,6 & 3,9 & 30,3 & 37,7 & 28,1 & \\
\hline Urbana & 56,4 & 4,4 & 27,6 & 36.7 & 31,3 & \\
\hline \multicolumn{7}{|l|}{ Área (\%) } \\
\hline GAM & 48,8 & 4,0 & 29,3 & 37,4 & 29,3 & \\
\hline Otra & 51,2 & 4,3 & 28,2 & 36,9 & 30,6 & \\
\hline Escolaridad (\%) & & & & & & 0,170 \\
\hline$\leq 6$ & 67,7 & 3,6 & 28,1 & 37,9 & 30,3 & \\
\hline$>6$ & 32,3 & 5,3 & 30,1 & 35,6 & 29,0 & \\
\hline Tabaquismo (\%) & & & & & & 0,997 \\
\hline No & 88,6 & 4,2 & 28,7 & 37,2 & 29,9 & \\
\hline Sí & 11,4 & 4,3 & 29,3 & 36,7 & 29,7 & \\
\hline Alcohol (\%) & & & & & & 0,081 \\
\hline No & 59,2 & 4,6 & 27,3 & 36,7 & 31,4 & \\
\hline Sí & 40,8 & 3,6 & 31,0 & 37,8 & 27,7 & \\
\hline
\end{tabular}

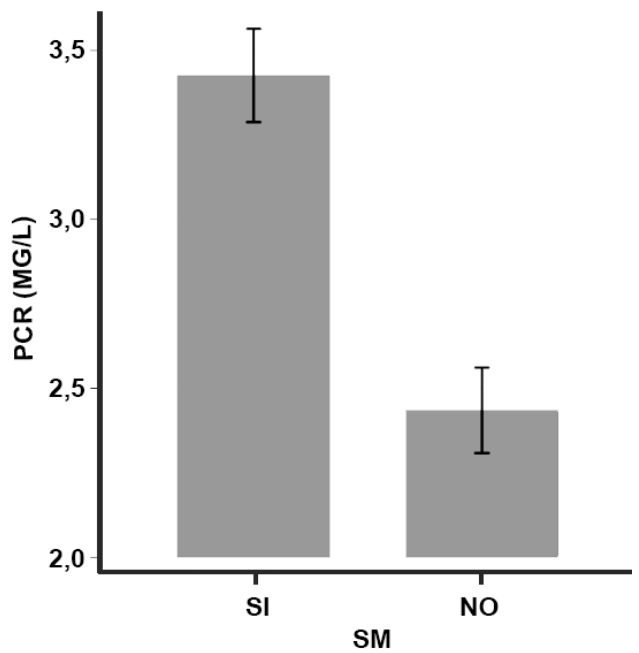

Fig. 1. Niveles de PCR de la población nacida entre 1945 y 1955 según presencia de síndrome metabólico ( $n=2273)$, Costa Rica. 


\section{CUADRO 2}

Prevalencia del SM en la población costarricense nacida entre 1945 y 1955 según cuartil de PCR, Costa Rica

\begin{tabular}{|c|c|c|c|c|c|c|c|}
\hline \multirow[b]{2}{*}{ Variable } & \multirow[b]{2}{*}{$\begin{array}{c}\text { Total } \\
(n=2273)\end{array}$} & \multicolumn{6}{|c|}{ Cuartil de PCR } \\
\hline & & $\mathbf{P}$ & $\begin{array}{c}1 \\
<1,00 \\
(n=95)\end{array}$ & $\begin{array}{c}2 \\
1,00-2,99 \\
(n=654)\end{array}$ & $\begin{array}{c}3 \\
3,00-3,99 \\
(n=844)\end{array}$ & $\begin{array}{c}4 \\
\geq 4,00 \\
(n=680)\end{array}$ & $\begin{array}{c}\text { p para la } \\
\text { tendencia }\end{array}$ \\
\hline Total & 53,6 & & 27,4 & 39,9 & 56,0 & 67,4 & $<0,0001$ \\
\hline \multicolumn{8}{|l|}{ Sexo } \\
\hline Hombre & 34,2 & $<0,001$ & 25,8 & 26,2 & 38,5 & 44,2 & $<0,0001$ \\
\hline Mujer & 66,8 & & 30,3 & 55,2 & 67,1 & 76,2 & $<0,0001$ \\
\hline \multicolumn{8}{|l|}{ Zona } \\
\hline Rural & 48.7 & $<0,001$ & 18,0 & 36,0 & 51,5 & 63,0 & $<0,0001$ \\
\hline Urbana & 57,4 & & 33,9 & 43,2 & 59,7 & 70,4 & $<0,0001$ \\
\hline \multicolumn{8}{|l|}{ Área } \\
\hline Otra & 50,6 & 0,005 & 22,9 & 36,7 & 54,0 & 63,1 & $<0,0001$ \\
\hline GAM & 56,4 & & 31,9 & 42,8 & 57,9 & 71,6 & $<0,0001$ \\
\hline \multicolumn{8}{|l|}{ Escolaridad } \\
\hline$\leq 6$ & 54,5 & 0,198 & 23,2 & 41,1 & 56,4 & 68,3 & $<0,0001$ \\
\hline$>6$ & 51,6 & & 33,3 & 37,6 & 55,2 & 65,3 & $<0,0001$ \\
\hline \multicolumn{8}{|l|}{ Tabaquismo } \\
\hline No & 55,8 & & 28,6 & 41,7 & 57,9 & 70,3 & $<0,0001$ \\
\hline Sí & 36,7 & & 18,2 & 26,3 & 41,0 & 44,2 & $<0,0001$ \\
\hline \multicolumn{8}{|l|}{ Alcohol } \\
\hline No & 57,1 & $<0,001$ & 32,3 & 42,8 & 60,9 & 68,6 & $<0,0001$ \\
\hline Sí & 48,5 & & 18,2 & 36,2 & 49,1 & 65,4 & $<0,0001$ \\
\hline \multicolumn{8}{|c|}{ Circunferencia } \\
\hline Normal & 19,8 & $<0,001$ & 17,8 & 18,0 & 22,6 & 19,3 & $<0,0001$ \\
\hline Elevada & 79,3 & & 59,1 & 75,6 & 77,7 & 83,5 & $<0,0001$ \\
\hline \multicolumn{8}{|l|}{ CT } \\
\hline Normal & 51,7 & $<0,001$ & 26,1 & 37,9 & 53,9 & 66,4 & $<0,0001$ \\
\hline Elevado & 64,7 & & 42,9 & 51,6 & 69,6 & 72,0 & $<0,0001$ \\
\hline \multicolumn{8}{|l|}{ C-HDL } \\
\hline Normal & 25,2 & $<0,001$ & 13,0 & 16,8 & 26,4 & 40,5 & $<0,0001$ \\
\hline Bajo & 64,7 & & 40,8 & 53,7 & 67,5 & 75,1 & $<0,0001$ \\
\hline \multicolumn{8}{|l|}{ PA } \\
\hline Normal & 26,8 & $<0,001$ & 9,1 & 19,6 & 27,2 & 38,7 & $<0,0001$ \\
\hline Elevada & 77,7 & & 52,5 & 65,8 & 78,2 & 88,3 & $<0,0001$ \\
\hline \multicolumn{8}{|l|}{ Glicemia } \\
\hline Normal & 41,4 & $<0,001$ & 16,2 & 29,8 & 43,1 & 55,7 & $<0,0001$ \\
\hline Elevada & 87,5 & & 66,7 & 77,5 & 89,4 & 94,2 & $<0,0001$ \\
\hline
\end{tabular}




\section{CUADRO 3}

Coeficiente de correlación de Spearman entre la PCR y distintos componentes del síndrome metabólico

\begin{tabular}{lccc}
\hline Factor & $\boldsymbol{r}$ & $\boldsymbol{p}$ & PSup \\
\hline CC & 0,308 & $<0,0001$ & 67,8 \\
C-HDL & $-0,068$ & 0,0013 & 58,6 \\
CT & 0,065 & 0,0020 & 53,5 \\
HbA1c & 0,196 & $<0,0001$ & 55,2 \\
PA & 0,085 & $<0,0001$ & 57,0 \\
\hline
\end{tabular}

\section{CUADRO 4}

Odds ratios e intervalos de confianza del 95\% para el SM y sus componentes por cuartil de PCR

\begin{tabular}{|c|c|c|c|c|}
\hline \multirow[b]{2}{*}{ Variable } & \multicolumn{4}{|c|}{ Cuartil de PCR } \\
\hline & $\begin{array}{c}1 \\
<1,00 \\
(n=95) \\
\end{array}$ & $\begin{array}{c}2 \\
1,00-2,99 \\
(n=749)\end{array}$ & $\begin{array}{c}3 \\
3,00-3,99 \\
(n=939)\end{array}$ & $\begin{array}{c}4 \\
\geq 4,00 \\
(n=775)\end{array}$ \\
\hline \multicolumn{5}{|l|}{ SM } \\
\hline Modelo 1 & 1 & $1,62(0,98-2,66)$ & $2,89(1,77-4,74)$ & $3,98(2,39-6,60)$ \\
\hline Modelo 2 & 1 & $1,64(0,99-2,70)$ & $3,07(1,86-5,06)$ & $4,26(2,55-7,12)$ \\
\hline \multicolumn{5}{|l|}{$\mathrm{CC}$} \\
\hline Modelo 1 & 1 & $1,82(1,05-3,15)$ & $4,22(2,45,-7,27)$ & $7,20(4,13-12,54)$ \\
\hline Modelo 2 & 1 & $1,84(1,06-3,19)$ & $4,33(2,51,-7,49)$ & $7,70(4,40-13,47)$ \\
\hline \multicolumn{5}{|l|}{ PA } \\
\hline Modelo 1 & 1 & $1,10(0,70-1,72)$ & $1,77(1,13-2,76)$ & $1,72(1,09-2,70)$ \\
\hline Modelo 2 & 1 & $1,07(0,68-1,67)$ & $1,83(1,17-2,87)$ & $1,78(1,12-2,83)$ \\
\hline \multicolumn{5}{|l|}{$\mathrm{CT}$} \\
\hline Modelo 1 & 1 & $1,40(0,89-2,18)$ & $1,36(0,88-2,11)$ & $1,50(0,95-2,36)$ \\
\hline Modelo 2 & 1 & $2,03(0,90-4,61)$ & $1,82(0,81-4,07)$ & $1,86(0,82-4,24)$ \\
\hline \multicolumn{5}{|l|}{ C-HDL } \\
\hline Modelo 1 & 1 & $1,52(0,98-2,35)$ & $2,45(1,58-3,81)$ & $2,89(1,82-4,58)$ \\
\hline Modelo 2 & 1 & $1,60(1,03-2,50)$ & $2,70(1,72-4,23)$ & $3,18(1,99-5,10)$ \\
\hline \multicolumn{5}{|l|}{$\mathrm{HbA} 1 \mathrm{c}$} \\
\hline Modelo 1 & 1 & $0,98(0,57-1,65)$ & $1,41(0,84-2,37)$ & $1,56(0,92-2,65)$ \\
\hline Modelo 2 & 1 & $1,00(0,59-1,70)$ & $1,49(0,88-2,52)$ & $1,68(0,98-2,86)$ \\
\hline
\end{tabular}

Modelo 1: ajustado por edad, sexo, zona de residencia

Modelo 2: ajustado por edad, sexo, zona de residencia, tabaquismo, consumo de alcohol y escolaridad

Finalmente, el riesgo de sufrir evento cardiovascular en 10 años aumenta conforme incrementa el nivel de PCR, notándose un incremento importante en las mujeres las cuales pasan de un riesgo de $9,5 \%$ a alrededor del $16 \%$ (Cuadro 5). Por otro lado, las personas con niveles de PCR $>3 \mathrm{mg} / \mathrm{L}$ presentan un riesgo cardiovascular promedio de $16,8 \%$ y la diferencia es significativa con respecto a las personas que presentan niveles menores de $3 \mathrm{mg} / \mathrm{L}(p<0,001)$. Se determinó una correlación significativa $(p<0,0001)$, pero modesta $(r=0,1035)$ entre PCR y el riesgo cardiovascular. Además, la probabilidad de que el riesgo de sufrir evento cardiovascular sea mayor en una persona con nivel de PCR mayor a $3 \mathrm{mg} / \mathrm{L}$ es de $54,6 \%$, por lo que se considera un efecto pequeño. 


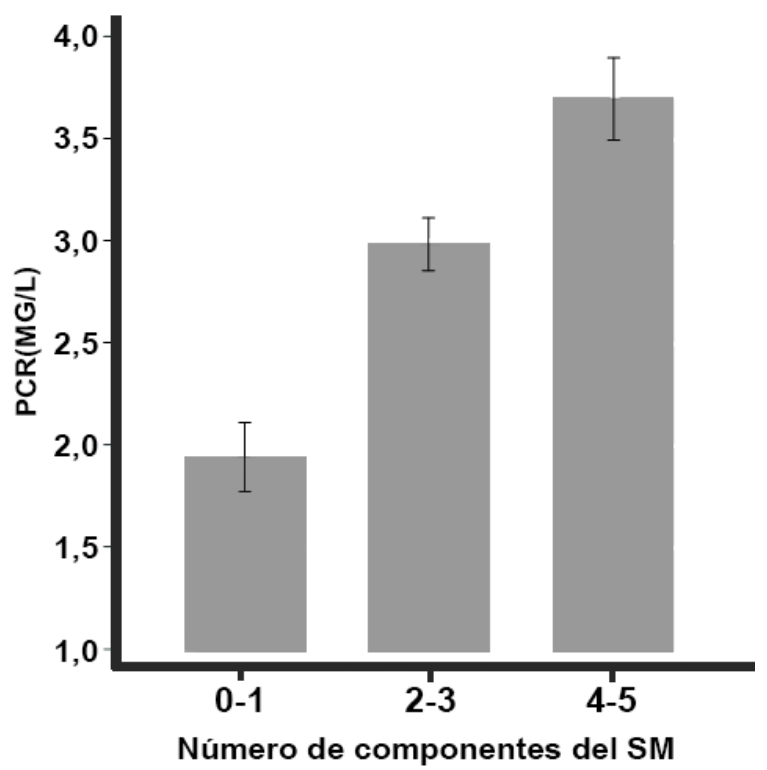

Fig. 2. Niveles de PCR de la población nacida entre 1945 y 1955 según la cantidad de componentes del síndrome metabólico $(n=2273)$, Costa Rica.

\section{CUADRO 5}

Riesgo de sufrir evento cardiovascular en 10 años por estrato de la población según diferentes niveles de PCR, Costa Rica

\begin{tabular}{|c|c|c|c|c|c|}
\hline \multicolumn{6}{|c|}{ Cuartil de PCR (mg/L) } \\
\hline Variable & $\begin{array}{c}1 \\
<1,00 \\
(n=95)\end{array}$ & $\begin{array}{c}2 \\
1,00-2,99 \\
(n=654)\end{array}$ & $\begin{array}{c}3 \\
3,00-3,99 \\
(n=844)\end{array}$ & $\begin{array}{c}4 \\
\geq 4,00 \\
(n=680)\end{array}$ & $\begin{array}{l}\text { p para la } \\
\text { diferencia }\end{array}$ \\
\hline Total & 14,1 & 15,0 & 16,1 & 16,8 & $<0,001$ \\
\hline \multicolumn{6}{|l|}{ Sexo } \\
\hline Hombre & 16,5 & 17,1 & 19,3 & 19,9 & $<0,0001$ \\
\hline Mujer & 9,5 & 12,6 & 14,1 & 15,7 & $<0,0001$ \\
\hline \multicolumn{6}{|l|}{ Zona } \\
\hline Rural & 14,1 & 14,9 & 16,6 & 16,7 & $<0,0001$ \\
\hline Urbana & 14,0 & 15,0 & 15,7 & 16,9 & $<0,0001$ \\
\hline \multicolumn{6}{|l|}{ Área } \\
\hline Otra & 13,6 & 15,2 & 16,4 & 16,7 & $<0,0001$ \\
\hline GAM & 14,5 & 14,8 & 15,9 & 16,9 & $<0,0001$ \\
\hline \multicolumn{6}{|l|}{ Escolaridad } \\
\hline$\leq 6$ & 14,4 & 15,3 & 16,4 & 17,2 & $<0,0001$ \\
\hline$>6$ & 13,6 & 14,3 & 15,5 & 16,0 & $<0,0001$ \\
\hline \multicolumn{6}{|l|}{ Tabaquismo } \\
\hline No & 13,0 & 14,0 & 15,3 & 15,9 & $<0,0001$ \\
\hline Sí & 21,9 & 21,8 & 22,1 & 23,7 & $<0,0001$ \\
\hline \multicolumn{6}{|l|}{ Alcohol } \\
\hline No & 14,1 & 14,6 & 16,2 & 16,8 & $<0,0001$ \\
\hline Sí & 14,0 & 15,4 & 15,9 & 16,9 & $<0,0001$ \\
\hline
\end{tabular}




\section{DISCUSIÓN}

El estudio determinó que un grupo importante de la población presenta síndrome metabólico. Además, la prevalencia es superior en las mujeres.

Se determinó una correlación positiva entre SM y concentraciones de PCR. Investigaciones previas han señalado que el SM está asociado con elevados niveles de PCR (Yudkin et al., 1999; Rutter et al., 2004; Bo et al., 2005). Los análisis determinaron asociaciones significativas con todos los componentes del SM; sin embargo, el tamaño del efecto resulta pequeño en algunos de los componentes. La relación más fuerte de la PCR se presentó con la CC convirtiéndolo en el factor de mayor relevancia del estudio dada la presencia de un efecto de cierta importancia; sin embargo, Fröhlich et al. (2000) señalan que puede no ser apropiado considerar las variables en forma aislada dado que el SM ocurre por la acción simultánea de un grupo de características. Al igual que en otros estudios (Fröhlich et al., 2000; Ye et al., 2007), en esta investigación se comprobó que los niveles de PCR aumentan conforme incrementa el número de componentes del SM.

En términos generales, los resultados del estudio coinciden con los hallazgos de otros grupos de investigación. Se ha mencionado que personas de mediana edad (Koenig et al., 1999) así como en grupos de edades avanzadas (Tracy et al., 1997), los niveles de PCR están correlacionados positivamente con medidas de adiposidad y con el descenso en las concentraciones de C-HDL. Esta relación negativa con C-HDL expone la tesis de que los procesos inflamatorios pueden verse favorecidos por la presencia de niveles bajos de lipoproteínas de alta densidad C-HDL (García, Bulló, Balanzà, \& Salas, 2006; Huang et al., 2008).

Después de ajustar por edad, sexo, zona, tabaquismo, consumo de alcohol y escolaridad, la probabilidad de tener niveles elevados de PCR aumenta con cierta relevancia en las personas con SM y con elevada circunferencia de la cintura, así como en los que presentan bajos niveles de CHDL. Esto evidencia que la asociación entre PCR y CC, así como con C-HDL es independiente del efecto de otras variables confusoras. Por otro lado, la incorporación de las personas con niveles de PCR $>10 \mathrm{mg} / \mathrm{L}$ excluidas inicialmente, no modificaron en gran medida las conclusiones del estudio.

También es importante considerar que si bien no se estudió a profundidad la relación entre PCR y riesgo cardiovascular, los datos evidenciaron el crecimiento de las probabilidades de sufrir eventos en los grupos de personas con elevadas concentraciones de PCR. Si bien estas probabilidades son mayores en los hombres, se observó un crecimiento considerable en las mujeres cuando incrementan los niveles de PCR. Aunque el poder predictivo de dicha proteína no ha sido completamente establecido (Pepys, 2005; Nilsson, 2005), es de suma importancia poner atención a las relaciones encontradas que la señalan como un importante factor de riesgo cardiovascular (Ridker, Cushman, Stampfer, Tracy y Hennekens, 1997; Saleh et al., 2005).

En conclusión, los niveles de PCR incrementan en las personas con presencia de SM y la obesidad se constituye en el factor que muestra mayor fuerza de asociación. Además, el riesgo de sufrir evento cardiovascular es mayor en las personas que presentan altos niveles de PCR.

Es importante destacar que las correlaciones entre PCR y SM así como entre PCR y riesgo cardiovascular que se hallaron en el estudio, podrían ser indicadores de que concentraciones elevadas de PCR estarían asociadas con un mayor riesgo de sufrir un evento cardiovascular en las personas costarricenses. El tratamiento de los factores del SM podrían ayudar a controlar los niveles de PCR en esta población y con ello contribuir a la disminución de la posibilidad de apariciones de eventos cardiovasculares. Programas de promoción de la salud para controlar y mejorar la detección del SM y sus complicaciones serían de gran relevancia.

Finalmente rescatar que la naturaleza de corte transversal de la muestra no permite establecer una relación de causa y efecto entre las variables. Además, los análisis realizados se 
fundamentaron en mediciones de PCR de una muestra de sangre, lo cual no permite visualizar variaciones individuales en las concentraciones de PCR, lípidos o glucosa (Ye et al., 2007).

\section{AGRADECIMIENTOS}

Agradecemos al proyecto "Costa Rica: Estudio de longevidad y envejecimiento saludable (CRELES)", un proyecto de investigación de la Universidad de Costa Rica, realizado por el Centro Centroamericano de Población (CCP) y de la Universidad de California-Berkeley, en colaboración con el Instituto. de Investigaciones en Salud, y los laboratorios del Hospital San Juan de Dios y la Oficina de Salud, UCR. Investigadores principales: Luis Rosero-Bixby y William H. Dow. Co-investigadores: Xinia Fernández y Gilbert Brenes-Camacho. Investigadores colaboradores: Ericka Méndez, Guido Pinto, Hannia Campos, Kenia Barrantes, Alberto Cubero, Fernando Coto, Pamela Jiménez, Jesús Granados y Yesi González. Personal de campo: José Solano, Julio Palma, Jenny Méndez, Maritza Aráuz, Mabelyn Gómez, Marcela Rodríguez, Geovanni Salas, Jorge Vindas, Katthya Alvarado, Randall González, Roberto Patiño, Carlos Robert y Jimmy Navarro.

\section{REFERENCIAS}

Albert, M. A., Glynn, R. J., \& Ridker, P. M. (2003). Plasma concentration of C-reactive protein and the calculated Framingham coronary heart disease risk score. Circulation, 108(2), 161-165. doi:10.1161/01.CIR.0000080289.72166.CF

Arcari, A., Zito, F., Di Castelnuovo, A., De Curtis, A., Dirckx, C., \& Arnout, J. (2008). C reactive protein and its determinants in healthy men and women from European regions at different risk of coronary disease: the IMMIDIET Project. Journal of Thrombosis and Haemostasis, 6(3), 436-443. doi:10.1111/j.1538-7836.2007.02851.x

Bo, S., Gentile, L., Ciccone, G., Baldi, C., Benini, L., Dusio, F., ... Pagano, G.F. (2005). The metabolic syndrome and high Creactive protein: prevalence and differences by sex in a Southern-European population-based cohort. Diabetes/Metabolism Research and Reviews, 21(6), 515-524. doi:10.1002/dmrr.561

Danesh, J., Wheeler, J. G., Hirschfield, G. M., Eda, S., Eiriksdottir, G., Rumley, A., ... Gudnason, V. (2004). C-reactive protein and other circulating markers of inflammation in the prediction of coronary heart disease. New England Journal of Medicine, 350(14), 1387-1397. doi:10.1056/NEJMoa032804

Dow, W. H., Brenes, G. y Rosero, L. (2013). CRELES: Costa Rican Longevity and Healthy Aging Study, Retirement Cohort. Methods, Wave 1. Berkeley, CA: Department of Demography, University of California. Recuperado de http://www.creles.berkeley.edu/pdf/Methods_w3.pdf

Fröhlich, M., Imhof, A., Berg, G., Hutchinson, W. L., Pepys, M. B., Boeing, H., ... Koenig, W. (2000). Association between Creactive protein and features of the metabolic syndrome: a population-based study. Diabetes Care, 23(12), 18351839. doi:10.2337/diacare.23.12.1835

García, P., Bulló, M., Balanzà, R., \& Salas, J. (2006). C-reactive protein, adiposity and cardiovascular risk factors in a Mediterranean population. International Journal of Obesity, 30(3), 468-474. doi:10.1038/sj.ijo.0803182

Grundy, S. M., Cleeman, J. I., Daniels, S. R., Donato, K. A., Eckel, R. H., Franklin, B. A., . . Costa, F. (2005). Diagnosis and management of the metabolic syndrome. Circulation, 112(17), 2735-2752. doi:10.1161/CIRCULATIONAHA.105.169404

Huang, J., Parish, R., Mansi, I., Yu, H., Kennen, E. M., Davis, T., \& Carden, D. (2008). Non-high-density lipoprotein cholesterol in patients with metabolic syndrome. Journal of Investigative Medicine, 56(7), 931-936. doi:10.2310/JIM.0b013e318182080a 
Koenig, W., Sund, M., Fröhlich, M., Fischer, H. G., Löwel, H., Döring, A., . . Pepys, M. B. (1999). C-reactive protein, a sensitive marker of inflammation, predicts future risk of coronary heart disease in initially healthy middle-aged men. Circulation, 99(2), 237-242. doi:10.1161/01.CIR.99.2.237

Mendall, M. A., Patel, P., Ballam, L., Strachan, D., \& Northfield, T. C. (1996). C reactive protein and its relation to cardiovascular risk factors: a population based cross sectional study. BMJ, 312(7038), 1061-1065. doi:10.1136/bmj.312.7038.1061

Nilsson, J. (2005). Crp - marker or maker of cardiovascular disease? Arteriosclerosis, Thrombosis, and Vascular Biology, 25(8), 1527-1528. doi:10.1161/01.ATV.0000174796.81443.3f

Pepys, M. B. (2005). Crp or not crp? that is the question. Arteriosclerosis, Thrombosis, and Vascular Biology, 25(6), 10911094. doi:10.1161/01.ATV.0000169644.88847.28

Ridker, P. M. (2003). C-reactive protein: a simple test to help predict risk of heart attack and stroke. Circulation, 108, 8185. doi:10.1161/01.cir.0000093381.57779.67

Ridker, P. M., Buring, J. E., Cook, N. R., \& Rifai, N. (2003). C-reactive protein, the metabolic syndrome, and risk of incident cardiovascular events. Circulation, 107(3), 391-397. doi:10.1161/01.CIR.0000055014.62083.05

Ridker, P., Cushman, M., Stampfer, M., Tracy, R., \& Hennekens, C. (1997). In- flammation, aspirin, and the risk of cardiovascular disease in apparently healthy men. New England Journal of Medicine, 336(14), 973-979. doi:10.1056/NEJM199704033361401

Ridker, P., Rifai, N., Rose, L., Buring, J., \& Cook, N. (2002). Comparison of c-reactive protein and low-density lipoprotein cholesterol levels in the prediction of first cardiovascular events. New England Journal of Medicine, 347(20), 15571565. doi:10.1056/NEJMoa021993

Rutter, M. K., Meigs, J. B., Sullivan, L. M., D’Agostino, R. B., \& Wilson, P. W. (2004). C-reactive protein, the metabolic syndrome, and prediction of cardiovascular events in the Framingham Offspring Study. Circulation, 110(4), 380385. doi:10.1161/01.CIR.0000136581.59584.0E

Saleh, N., Svane, B., Hansson, L. O., Jensen, J., Nilsson, T., Danielsson, O., \& Tornvall, P. (2005). Response of serum Creactive protein to percutaneous coronary intervention has prognostic value. Clinical Chemistry, 51(11), 21242130. doi:10.1373/clinchem.2005.048082

Sattar, N., Gaw, A., Scherbakova, O., Ford, I., O’Reilly, D. S., Haffner, S. M., ... Shepherd, J. (2003). Metabolic syndrome with and without C-reactive protein as a predictor of coronary heart disease and diabetes in the west of Scotland coronary prevention study. Circulation, 108(4), 414-419. doi:10.1161/01.CIR.0000080897.52664.94

Tracy, R. P., Psaty, B. M., Macy, E., Bovill, E. G., Cushman, M., Cornell, E. S., \& Kuller, L. H. (1997). Lifetime smoking exposure affects the association of C-reactive protein with cardiovascular disease risk factors and subclinical disease in healthy elderly subjects. Arteriosclerosis, Thrombosis, and Vascular Biology, 17(10), 2167-2176. doi:10.1161/01.ATV.17.10.2167

Wilson, P.W.F., D’Agostino, R. B., Levy, D., Belanger, A. M., \& Silbershatz, H. (1998). Prediction of coronary heart disease using risk factor categories. Circulation, 97, 1837-1847. doi:10.1161/01.CIR.97.18.1837

Yang, T., Chu, C., Hsieh, P., Hsu, C., Chou, Y., Yang, S., . . Sun, C. (2013, 4). C-reactive protein concentration as a significant correlate for metabolic syndrome: A Chinese population-based study. Endocrine, 43(2), 351-359. doi:10.1007/s12020-012-9743-7

Ye, X., Yu, Z., Li, H., Franco, O. H., Liu, Y., \& Lin, X. (2007). Distributions of C-reactive protein and its association with metabolic syndrome in middle-aged and older Chinese people. Journal of the American College of Cardiology, 49(17), 1798-1805. doi:10.1016/j.jacc.2007.01.065

Yudkin, J. S., Stehouwer, C. D., Emeis, J. J. y Coppack, S. W. (1999). C-reactive pro- tein in healthy subjects: Associations with obesity, insulin resistance, and endothelial dysfunction. Arteriosclerosis, Thrombosis, and Vascular Biology, 19(4), 972-978. doi:10.1161/01.ATV.19.4.972 